www.jmscr.igmpublication.org

Impact Factor 5.84

Index Copernicus Value: 83.27

ISSN (e)-2347-176x ISSN (p) 2455-0450

crossref DOI: _https://dx.doi.org/10.18535/jmscr/v5i7.121

\title{
Incidence and Mortality of Post-Surgical Wound Sepsis in Surgery Wards of University of Port Harcourt Teaching Hospital, Port Harcourt
}

\author{
Author \\ Gbeneol .J. Tombari \\ Dept of Preventive and Social Medicine, College of Head Sciences, University of Port Harcourt, Nigeria \\ Email: gbeneol.tombari@gmail.com,Tel:+2348033426025
}

\begin{abstract}
Post-operative wound sepsis in 1050 patients who had clean and contaminated surgery were studied retrospectivelyin male female and children surgery wards of the University of Port Harcourt Teaching Hospital from January 1986 to December 1990. Subjects considered for the study were between ages 18 days to 82 years. Incidence of post-operative wound sepsis was $3.14 \%$ being $1.55 \%$ and $5.12 \%$ for the clean and contaminated operations respectively. The highest infection rate of a single operation was $16.3 \%$ from bowel resections. Mortality rate within the period under consideration was $0.19 \%$. The study is important in identifying those at risk of post-operative wound sepsis.
\end{abstract}

\section{INTRODUCTION}

Infection is the successful invasion, establishment and growth of micro-organism in the tissue of the host. Man is exposed to a series of microorganisms from the atmosphere, food and water consumed. Some organisms even inhabit the mouth, gastrointestinal, urogenital, respiratory tracts and the skin of man. Though presently, they do not cause symptoms because of their low virulence property, and are referred to as commensals.

When a patient gets infected after surgery and the infection is related to that surgery, (usually at the post-operative wound site) it is referred to as PostOperative Wound Sepsis. Staphylococcus aureus is the most common documented organism to infect surgical wounds. This can be explained from the fact that it is carried in $5 \%$ of people on all the hair bearing areas and up to $50 \%$ of people carry this organism in the nose. It is also a transient commensal on the skin of the hand together with pseudomonas, klebsiella and enterobacter species, which are found on the hands exposed to moisture, abrasions associated with chronic skin disease and nail bed lesions. The possibility of colonization with multiple antibiotic-resistant hospital bred staphylococcus aureus is a recognized major risk in patients' surgical procedures (Bailey and Love).

A pioneer study carried out by Montefore et al., (1979) in the University College Hospital, Ibadan, Nigeria indicated a $4.49 \%$ rate of infection. This is in agreement with studies carried out in the United State of America with figures between 5-10\%.

In a preliminary report ofa prospective study of surgical wound infection over one year period at 
Military Hospital, Benin City, Abayomi and Ferreira (1979) provided $7.63 \%$ as an overall wound infection rate in Nigeria. He stressed the importance of surface contamination as a major factor in the pathogenesis of surgical wound infection. The incidence of $66 \%$ cultured microorganism being staphylococcus aureus. $40 \%$ of culture were mixed. Common organisms cultured in this study were resistant to penicillin, streptomycin, ampicillin, septrin and tetracycline. It is debatable that chemoprophylaxis whilst awaiting sensitivity reports in the management of surgical wounds is ineffectual. Ferreira then proposed the need for each institution to design its own antibiotic policy and that periodic studies be conducted to test the continued veracity and reliability of such scientifically designed policy.

Christie (1981) reported that the spread of infection within a community from one person to another depends on the virulence of infectivity of the organism, the incubation period of the disease, the level of susceptibility or immunity among the members of the community and on the living conditions of the people.

In 1989, Otukenefor and Datubo-Brown reported a bacteriological study of wound infections in the surgery wards of a Teaching Hospital. The study revealed that $50 \%$ of the seventy nine wound swabs taken were caused by staphylococcus aureus.

This study was aimed at providing data on incidence of post-surgical wound infection in the University of Port Harcourt Teaching Hospital.

\section{MATERIALS AND METHODS}

This study was conducted within a period of 5 years (1986 - 1990) in the University of Port Harcourt Teaching Hospital. The data of 2100 patients comprising of adult males, females and children were collected from the registers in male surgical, female surgical and children surgical wards respectively.

Information on each patient selected were carefully obtained by an in-depth study of the patients' case notes (folder), which contain the house officer's detailed clerking at patient's presentation to clinic, casualty or referral before admission to the three surgical wards above. The day to day condition of the patients were studied. Every necessary procedure were carefully observed pre-operatively and post-operatively.

The symptoms of post-operative wound sepsis like fever, undue pains at the operative site and signs such as exquisite tenderness, hyperaemic incision edges and the discharge of pus from the stitches and incision site (which are indices of wound sepsis) were carefully recorded.

The surgical procedures were divided into clean and contaminated groups (Table 1 and 2) respectively

\section{EXCLUSION CRITERIA}

1. Evidence of sepsis at the operative site prior to surgery or pus seen at laparotomy such as drainage of an appendicular mass or pelvic abscess.

2. Oral, anal and urogenital surgeries below the level of the bladder

3. Files with incomplete records were also excluded

The duration of acquisition of the post-operative wound infection was determined by subtracting the date of appearance of pus at the operation site from the date of surgery, one which if less than 4 days was discarded as having been gotten before surgery. Records were rejected if there was any evidence of sepsis at the operative site prior to surgery or pus seen at laparotomy such as drainage of an appendicular mass or pelvic abscess.

\section{RESULTS}

The results of patients' records obtained from surgical wards of the hospital indicating the type of surgery, number and percentage infected were tabulated as shown in tables 1 and 2 below. The ages of patients' records considered ranged from 18 days to 82 years. 
Table 1: Incidence of Post-Surgical Wound Sepsis in Various Surgical Wards (SW)

\begin{tabular}{|l|c|c|c|c|c|c|}
\hline & Male SW & Female SW & Children SW & Total & Number Infected & \% Infected \\
\hline Herniorraphy & 199 & 60 & 77 & 336 & 4 & 1.2 \\
\hline Thyroidectomy & 7 & 18 & 1 & 26 & - & - \\
\hline Excisions & 9 & 19 & 8 & 36 & 1 & 2.8 \\
\hline Hydrocelectomy & 26 & - & 31 & 57 & 1 & 1.7 \\
\hline Prostatectomy & 62 & - & - & 62 & 2 & 3.2 \\
\hline Reduction of Volvolus & - & 1 & 6 & 7 & - & - \\
\hline Intussusception & - & 1 & 66 & 7 & 1 & 5.2 \\
\hline Others & 38 & - & 19 & 57 & 1 & 1.3 \\
\hline
\end{tabular}

Table 2: Contaminated Operation

\begin{tabular}{|l|c|c|c|c|c|c|}
\hline & Male SW & Female SW & Children SW & Total & Number Infected & \% Infected \\
\hline Appendicectomy & 70 & 178 & 26 & 274 & 5 & 1.8 \\
\hline Intestinal Obstruction & 23 & 36 & 12 & 71 & 5 & 7 \\
\hline Bowel Resection & 36 & 4 & 9 & 49 & 8 & 16.3 \\
\hline Closure of Perforation & 9 & - & 9 & 18 & 2 & 11.1 \\
\hline Strangulated Hernia & 25 & 5 & 5 & 35 & 2 & 2.8 \\
\hline Ruptured Appendix & 3 & 3 & 3 & 9 & 1 & 11.1 \\
\hline Others & 12 & - & 1 & 13 & 41 & 7.6 \\
\hline
\end{tabular}

\section{DISCUSSION}

The result in this study agrees with findings in other centres and is relevant within the scope of study of post-surgical wounds as seen in Nigerian practice. The importance of study of post-surgical wound sepsis contributes to the improvement and development of treatment and management of such patients.

The incidence of post-surgical wound sepsis in this 5 years study of clean and contaminated cases was recorded as $3.14 \%$, which is in consonant with the clean infection rate of $3.7 \%$ rate reported by Lawal et al., (1990) in Obafemi Awolowo University. This was also in agreement with Cruse, (1970) and Cruse and Foord, (1973). However, Altemiere, (1966) reported a higher rate (7.4\%) from a two and half year collaborative study of 15,613 consecutive operation done in five American University Centres. It is important to note that in Altemiere's study already infected cases prior to surgery were included whereas this present study excluded infected cases prior to surgery. This explains the high rate recorded by Altemiere's research.

The incidence of mortality from post-surgical wound sepsis in this study was $0.19 \%$. This percentage was gotten from 2 out of the 33 infected cases. Both cases presented as emergencies, both with a diagnosis of strangulated hernias that require bowel resection. The first of the two had his post-operative wound discharging pus on the $6^{\text {th }}$ post-operative day, and died 5 days later. The second case discharged pus from the operation wound site 9 days after surgery and died on the $37^{\text {th }}$ day after the operation. In this era of potent antibiotherapy, infection is a very rare cause of death. One cannot actually prove the cause of death as autopsy was not carried out nor put one's bet that they did not die from their primary surgical illness for which they presented late and probably only had a concomitant surgical wound sepsis.

The commonest operation in this hospital as shown in table 1 of this study is herniorrhaphy. Simple or uncomplicated hernias make up 336 and strangulated hernia 35, out of the 1050 sample. Both making up $35.3 \%$ of the surgical illness that presented in this hospital (UPTH). The second commonest procedure being appendicectomy making up $26.1 \%$.

For each of the surgical procedures done, the highest incidence of surgical wound sepsis is in bowel resection, in which $16.3 \%$ of the cases got infected by organisms that inhabit the gut. The next highest ranking procedure is closure of bowel perforations which comprised perforated typhoid ulcers and peptic ulcers. 
Furthermore, out of the 581 clean cases, only 9 of them ended up with wound sepsis while 24 of the 469 contaminated cases had post-operative wound sepsis. This gives $1.55 \%$ for clean operations and $5.12 \%$ for the contaminated operations. Hence contaminated operations have 3.3 times higher incidences of having post-operative wound sepsis when compared with clean operations. The contaminated state of a surgical procedure is hence a confounding factor to the development of post-operative wound sepsis.

\section{CONCLUSION}

Within the limits of available records under the study period and remote statistical errors, this study has been able to provide data on the incidence of post-surgical wound sepsis and some of its correlates which could serve as reference values for the University of Port Harcourt Teaching Hospital.

It has also been established that the commonest surgical procedure causing post-operative wound sepsis is bowel resections (16.3\%) followed by closure of perforation and surgery for ruptured appendix $(11.1 \%)$. The therefore has established that intra operative wound state, either clean or contaminated is the main determinant, and adequately predicts the risk of subsequent postoperative wound sepsis in general surgical procedures. The findings in this research also present the identification of the pathogens and the categorization of operations that must be the target of appropriated prophylaxis at the time of operation or in the very early post-operative period.

\section{REFERENCES}

1. Abayomi A and Ferreira J (1979). Surgical Wound Infection in a General Hospital - A Preliminary Report. W. Afri. J.Surgery. 3(2): $57-64$

2. Altermiere N.A (1966). Control of Wound Infection. J. R. CSE., 11(4): 271.
3. Christie A.B (1981). Hospital Infection A Worldwide Problem. Post Graduate Doctor. African. 3(2) .

4. Cruse P.J.E (1970). Surgical Wound Sepsis. Cann. Med. Assoc. J., 102: 251 258.

5. Cruse P.J.E and Foord R (1973). A Five Years Prospective Study of 23,649 Surgical Wounds. Arch. Surg., 107: 206 210.

6. Lawal O.O, Adejuyigbo $\mathrm{O}$ and Oluwole S.F (1990). The Predictive Value of Bacterial Contamination at Operation in Post- Operative Wound Sepsis. Afr. J. Med. Sci. 19: 173 - 179.

7. Montefiore et al (1990). Hospital Surveillance of Hospital Wound Infection - A Report from the Control of Infection Sub-Committee, University College Hospital, Ibadan, Nigeria. Med. J. 3(2)

8. Otokunefor T.V and Datubo-Brown D.D (1990). Bacteriology of Wound Infections in the Surgical Wards of a Teaching Hospital. W. Afr. J. Med., 9(4): 285 - 290. 